\title{
LXVII. Some experiments on the combustion of the diamond and other carbonaceous substances
}

\author{
Sir Humphry Davy LL.D. F.R.S. V.P.R.I.
}

To cite this article: Sir Humphry Davy LL.D. F.R.S. V.P.R.I. (1814) LXVII. Some experiments on the combustion of the diamond and other carbonaceous substances, Philosophical Magazine Series 1, 44:200, 429-438, DOI: 10.1080/14786441408637482

To link to this article: http://dx.doi.org/10.1080/14786441408637482

册 Published online: 27 Jul 2009.

Submit your article to this journal $\lceil\pi$

Џll Article views: 2

Q View related articles 
Some Experiments on the Combustion of the Diamond. 429

coralline (species unknown to me) is often met with. Near Dunraven large fossil nautili, and at Llanblethian delicate casts of cornua ammonis in calcareous spar. Shells of several other genera occur less frequently. The breccia above mentioned occurs, I believe, close to the blue lias at the mouth of Cadorton river.

Small oysters, nearly in a recent state, occur in the seams of clay between the layers.

\section{Sutton Stone.}

The Sutton or Silton stone which occurs near the Dunraven caves is of a greyish-white colour, and contains cockles, muscles and scollops converted into silex. The rock makes but irdifferent lime, as it contains much siliceous matter. It bears the weather well, as the copings of Swansea Castle, Neath Abbey, \&c. evince. The Sutton stone overlies the masses of rock which rise round and in front of the caves. These masses are calcareous, but mixed with much argil of a reddish brown or black colour; and it is curious, that this species of rock occurs no where else in Glamorganshire.

\section{Coal Basin.}

This important formation with its valuable beds of different coals, and argillaceous iron ore, has been well described by Mr. Martin. (Phil. Trans. 1806.) It comprises all the tract lying $N$. of a line drawn eastward from Taybach, along the hills behind Bridgend and Lantrissent to the extremity of the county. The iron ore is most abundant round Merthyr and at the upper part of Heath Valley. The picturesque scenes in the vales of Tawey, Neath, Dgmore, Rondda and Taaf, lie within its range. The momtain lime rises to the north of the basin at Castell Alorlais near Merthyr. A valuable bed of siliceous freestone is met with at Coity; it lies between the coal basin and mountain lime; it is also worked near Pyle. At Sutton $1 \frac{\mathrm{I}}{2}$ mile W. of Dunraven a valuable bed of calcareous freestone much used for ornamental masonry rests upon the lias near its junction with the mountain lime.

Dec. 3, 1814 .

LXVII. Some Experiments on the Combustion of the Diamond and other carbonaceous Sulbstances. By Sir Humper Davy, LL.D. F.R.S. V.P.R.I.*

$S_{\text {INCE it has been shown by various accurate experiments, that }}$ the diamoud and common carbonaceous substances consume nearly the same quantity of oxygen in combustion, and produce

* From the P'silosophical Trausactions for 1814, part ii. 


\section{Some Experiments on the Combustion of the Diamond.}

a gas having the same obvions qualities, a number of conjectures have been formed to explain the remarkable differences in the sensible qualities of these bodies, by supposing some ininute difference in their chenical composition : these conjectures have been often discussed, it will not be necessary therefore to dwell upon them. MM. Biot and Arago, from the high refractive power of the dianond, have supposed that it may contain hydrogen. I ventured to suggest in my third Bakerian Lecture, from the circumstance of its non-conducting power, and from the action of potassium upon it, that a minute portion of oxyger may exist in it; and in my Account of some new Experiment. on the Auoric Compounds*, I hazarded the idea that it might be the carbonaceous principle combined with some new light and subtile element of the class of supporters of combustion. M. Guyton de Morveau, who conceived he had proved by experiments made fourteen years ago, that common carbonaceous: substances were oxides of diamonds, from lis last researches, conducted in the same manner as those of Messrs. Allen and Pepy, seems still inclined to adopt this opinion, though in admitting a much smaller quantity of oxygen than he originally supposed in charcoal; and he considers the diamond as pure carbonaceous matter, containing, possibly, some atoms of water of̈ crystallization.

I have long had a desire of making some now experiments on the combustion of the diamond and other carbonaceous substances; and this desire was increased by the new facts ascertained with respect to iodine, which by uniting to lydrogen afforis an acid so analogous to muriatic acid, that it was for some time confonded with that substance. My object in these experiments was, to examine minutely whetier any peculiar matter was separated from the diamond during its combustion, and to determine whether the gas, formed in this process, was precisely the same in its miuute chemical nature, as that formed in the combustion of common charcoal. I have lately been abie to accompish my wishes; I shall now have the honour of communicating my results to the Royal Society.

During a stay that I made at Florence in the end of March aud beginnin' of April, I made several experiments on the conbustion of the diamond, and of plumbago, by means of the great lens in the Cabinet of Natural History; the same instrunent as that employed in the first trials on the action of the solar heat on the diamond, instituted by Cosmo III. Grand Duke of 'Tuscany; and I have since made a series of researches on the combustion of different kinds of charcoal at Rome, in the laboratory

* Phil. Trans. for 1814, part i. p. T2,--Phil. Mag, p. 93: 
of the Academia Lyncei. In the first series I was honoured by the assistance of the Count Bardi, the Director, and Signior Gazzari, the Professor of Chemistry at the Florentine Museim: and in the last by that of Sig. Morrichini and Barlocei, Professors of the College Sapienza at Rome.

In the very first trials on the combustion of the diamond, I ascertained a circumstance that I believe has not been noticerl before; namely, that the dianond, when strongly ignited by the lens in a thin capsule of platinum perforated with many orfices, so as to admit a free circulation of air, contimes to burn in oxygen gas after being withdrawn from the focus. The light it affords is steady, and of so brilliant a red, as to be visible in the brightest sunshine; and the heat produced is so great, that in one experiment, in which three fragments of diamonds weighing 1.84 grain only were burnt, a fine wire of platinum used for attaching them to the tray was fused, and that some time after the diamonds were removed ont of the focus.

The knowledge of this circumstance enabled me to aropt a very simple apparatus and mode of operation in my researches, and to complete, in a few minutes, experiments which have been supposed to reriuire the presence of a bright sunshine for many hours.

My apparatus consisted of clear glass globes of the capacity of from fourteen to forty cubical inches, having single apertures to which stop-cocks were attached: a small hollow cylinder of platinum, which I use in experiments with the blow-pipe, was attached to one end of the stop-cock, and was mounted with a little perforated capsule of platinum for containing the diamond. When the experinent was to be made, the globe containing the capsule and the substance to be burned was exhausted by an excellent air-pump, and pure oxygen gas, made from hyperoxymuriate of potassa, admitted. The globe before and after the experiment was brought to the same temperature as the water over which the oxygen gas had remained. And as during the short time required for the combustion there was no sensible change either in the thermometer or barometer, no corrections for pressure or temporature were rendered necessary; the change of volume in the gas after the combustion, was estimater by means of a fine tube connected with a stop-cock, adapted br a proper screw to the stop-cock of the globe, and the absorption was judged of by the quantity of mercury that entered the tube, which afforded a measure so cxact that no alteration. however mimute, could be overlooked. As the elastic force of the vapour or water is the same at the same temperature, it was evicient, that if nny water fomod in these experiments, it would be deposited as dew or mist in the globe; and I am convined by direct triais, 


\section{Some Experiments on the Combustion of the Diamond.}

that a quantity of moisture not capable of bcing weighed by a balance sensible to the $\pi \%$ of a grain, is rendered evident by deposition on a polished glass surface *\%.

The diamonds were always heated to redness before they were introduced into the eapsule.

During the combustion of the diamond, the glass globe was kept cool by the application of water to that part of it immediately above the capsule, and where the heat was greatest.

In the first experiment, three diamonds, weighing together 1.63 grain, were entirely consumed, in a quantity of oxygen gas, more than three times as much as was nccessary to convert them into carbonic acid. In this case, after the combustion had once commenced, it continued without a fresh application of the lenss till there remained only a very thin piece of the largest diamond in contact with the capsule, and this by being brought into the focus rapidly disappeared. On restoring the globe to its original temperature, there was a very evident deposition of moisture; but on arranging the apparatus, so as to ascertain the change of volume of the gas, there entered only twenty-one grains of mercury. In this experiment, the cylinder of platinum had been fastened into the stop-cock by means of a sinall perforated cork : it seemed probable, when the small diminution of gas was considered, that the appearance of moisture might be owing to the production of vapour from this cork during the combustion, and the second experiment demonstrated that this was the case.

In this second experiment 1.94 grain of small diamonds were employed, and a glass globe of the capacity of 14.9 cubical inches. Soon arter the capsule was placed in the focus in bright sunshine, the diamonds burnt with great brilliancy, and continued to burn till they had considerably diminished in bulk; but their splendour of combustion gradually became less, and before they had apparently lost half of their volume the process ceased. By placing them a second time in the focus, after agitating the globe so as in ehange their places, the ecmbustion was again produced; but the light was much less vivid than before, and the combustion continued for a much shorter time. They were exposed to the concentrated rays a third and a fourth time; but after the fourth time they seemed incapable of burning, and though kept for some minutes in the focus, appeared to under-

* A piece of paper weighing a grain was introduced into a tube of about the capacity of four cubical inches, the exterior of which was gently beated by a candle; immediatcly a slight dew was perceptible in the interior of the upper part of the tuhe; the paper tahen out and weiched immediately in the balance above referred to, had not suffered any aly greciable timinutron. 
go no further diminution: two fragments remained, which, as it was afterwards found, weighed $\cdot 52$ of a grain; the barometer during the experiment was at $29 \cdot 9$ inches, the thermometer at $56^{\circ}$ Fahrenheit. When the original temperature of the globe was restored, there was not the slightest appearance of vapour or humidity; the interior was as clear as before the experiment, and there was no solid matter of any kind separated in the tray. The fragments of diamond which remained were not black, but bad lost their lustre like glims that has been acted on by fuoric acid, nor at any period of the process was any carbonaceous appearance perceived upon them. When the communication was male by the top-cock between the interior of the globe and a surface of mercury; a minute quantity entered equal to $1 \cdot 5$ grain only.

$A$ portion of the gas in the globe was transferred into a tube in the marcurial apparatus, and the oxygen it contained absorbed by the combustion of phosphorus; $3 . \bar{z}$ parts of gas heated in this way left a residuum of 2.5 parts. A portion of the gas was agitated with lime-water, when seven parts out of ten were absorbed. I exposed the gas which remained after the combustion of phosphorus to several tests; it had not only the obvious characters of carbonic acid, but exhibited exactly the same chemical phænomena. Potassium strongly heated in it in a sinall glass tube over mercury, burnt with a dull red light, and formed an alkaline product of the same intense black colour as that proluced by its combustion in the carbonic acid procured by the dissolution of marble: distilled water absorbed rather less than its own volume of the gas, aud became sulacid, sparkled by agitation, gained the taste and sinell of a solution of carbonic acid in water, precipitated in the same manner limewater, and when in excess redissolved the precipitate. To ascertain if this precipitate was exactly the same in composition as pure carbonate of lime, 1 made a sufficient quantity of it by pouring lime-water into the recipient containing the results of the first experiment; and after collecting and drying it at the temperature of $212^{\circ}$ Fahrenheit, I introduced a quantity of it contained in sone foil of platinum through mercury into a glass tube filled with mercury, and I heated in the same manner an equal quantity of finely powdered Carrara marble, and admitted to them equal quantities of solution of muriatic acid. In this trial, there was rather more elastic thid disengaged from the Carrara marble than from the carbonate of lime from the diamond; but on examining the foil of platinum after the experiment, I found that a little of the carbonate had not been acted upon: I tried two similar experiments, substituting bibulous paper instead of the metallic foils for infolding the carbonates;

Vol. 44. No.200. Dec. 1814. Ee the 


\section{Some Experiments on the Comlustion of the Diamond:}

the results were such as to show. that both substances afforded the same quantities of elastic flud.

I heated some of the carbonate from the diamond in a tube which contained potassium, and passed the potassium through it in vapour : there was ignition, and a substance of a dense black colour was formed; this substarce was acted on by dilute muriatic acid, when it left a fine black powder which burnt like lamp black, and when thrown into fused nitre seintillated and disappeared in the same manner as powdered charcoal.

The gas that remained in the second experiment, after the absorption of the carbonic acid gas, vivilly supported combustion, and diminished with nitrous gas; hut as the degree of purity of the oxygen gas with which the globe was filled had not been determined before the experiment, it was impossible to ascertain with precision, that no elastic matter had been emitted during the proess. Todetermine this point, I made a third experiment. A thin diamond weighing -93 of a grain was introduced into the platinum capsule, which was placed in a globe filled with water and inverted in water; some oxygen gas, the last portion from the decomposition of hyper-oxyunuriate of potassa, was thrown into the globe, so as to displace the water below the level of the capsule. The focus of the great lens was thrown upon the capsule, which with the diamond was instantly rendered dry by it, and the diamond soon entered into combustion and burnt as usual. After the process was finished, the carbonic acid was absorbed by lime-water, and the remaining gas, which equalled about one-third of the quantity of oxygen originally used, was compared analytically in several experiments with a portion of the same oxygen as that introduced into the globe, two measures of nitrous gas being added to a measure of each of the gases; the diminution was less by from $\frac{1}{100}$ to $T .0$ parts in the cases in which the gas that had been exposed to the action of the diamond was used; but this minute difference is what might have been expected, and which indeed could nut fail to exist, when it is considered thet, during the absorption of carbonic acid ges by water ard lime water, a small quantity of common air is always expelled from the water.

In this last experinent a small fragment of diamond remained unconsumed, which was similar in appearance to that mentioned in the second experiment, and its coluur, which was originaliy yellow, was rendered rather darker. In no one of the three experiments was there any distinct appearance of carbonization, when the process was stopped in consequence of the impurity of the gas; though the dianonds were of various colous and different lustres.

A piece of plumbage from Borrowdale in Cumberland, weigh- 


\section{Some Experiments on the Combustion of the Diamond. 433}

ing two grains, was exposed in the focus in the same manner as the diamond in the first and second experiments, having been previously heated red; the quantity of oxygen gas employed was 8.5 cubical inches: more than half the plumbago renained unconsumed, and during the combustion some brown ashes were produced. The phrnomena in this experiment were very different from those observed in the experiments on the diamond, the gas became clouded during the process, and there was a considerable deposition of dew on the interior of the globe. When the original temperature of the globe was restored, and the stop-cock opened, $96 \cdot 6$ grains of mercury entered, and drops of moisture even were observed condensed on the sides of the vesoel.

In the second series of experiments, charcoal formed by the action of sulphuric acid on oil of turpentine, and some produced during the formation of sulphuric ether, from which nitric acid had been distilled, and which afterwards had been strongly ignited, and charcoal of oak which had undergone the same process, were used.

Three grains of the charcoal from turpentine were employed, 2.5 of that from alcohol, and five grains of the charcoal of the oak : in all these instances of combustion the gas became clouded during the combustion, and when the original temperature of the globe was restored, moisture was found condensed in the interior; much the largest quantity in the experiment on the charcoal of oak, and the least in that on the charcoal procured from oil of turpentine. The charcoal from oak left a residuum of white ashes, which was principally carbonate of lime; that from oil of turpentine produced no residuum; that from alcohol, which was formed in a common process of the manufacture of ether, left a minute quantity of ashes, probably owing to the impurity of the sulphuric acid employed.

The quantity of mercury which entered the apparatus indicating the change of volume of the gas, was in the experiment on the charcoal of oil of turpentine ......... 107.5 grains

In that on the charcoal of alcohol ......... 194.5

In that on the charcoal of $\mathrm{ak} . \ldots \ldots \ldots \ldots .513 \cdot 3$

From the results of these different experiments, it appears evident, that the diamond affords no other substance by its combustion than pure carbonic axid gass; and that the process is merely a solution of diamond in oxygen, without any change in the volume of the gas; for the slighit absorption in the second experiment is scarcely more than a compensation for the volume occupied by the diamonds consumed.

It is likewise evident that in the combustion of the different knds of eharcoal, water is produced; and from the diminution I e 2 


\section{Some Experiments on the Combustion of the Diamond.}

of the volime of the gas, there is every reason to believe, that the water is formed by the combustion of hydrogen existing in the charcoal; and experiments which I have referred to, or detailed in my third Bakerian Lecture, prove the presence of hydrogen in common charcoal; and as the charcoal from the oil of turpentime left no resivium, no other cause but the presence of hydrogen can be charcoal for the diminution occasioned in the volume of the gas during its combustion.

M. Guyton de Morvea has noticed the production of water during the combustim of ylumbago from Keswick; and from these experiments it is most probable that it is formed in the process of combustion, for it is unlikely that water should remain in union with plumbago at a red heat; and in the various experiments that I have made on the ignition of plumbago by Voltaic electricity, I have never perceived the separation of any moisture, or the production of any gas; so thei it seenis most likely that it contains intimately combined hylrogen. It camnot be supposed that water exists in it in mion with oxide of iron, for in this case there would be no obvious cause for the diminution of the volume of the gas; and all analogy is in favour of the conclusion that the iron is in a metallic state.

The general tenor of the results of these experiments is opposed to the opinion, that common carbonaceous substances differ from the diamond by containing oxygen; for in this case they ought to increase and not diminish the volume of oxygen : nor, on the other hand, is it favourable to the supposition that the diamond contains oxygen, for the difference in the quantity of carbonic acid produced in the different experiments, is no more than may be rensonably ascribed to the generation of water, in the combustion of the common carbonaceons substances; and the results of the experiments, to which I have referred in the beginning of this paper on the action of potassium on the diamond, may be easily accounted for from other circumstancest.

That charcoal is more inflammable than the diamond may be explained from the looseness of its texture, and from the hydrogen it contains; but the diamond appears to burn in oxygen with as much facility as plumbago, so that at least one distinction supposed to exist between the diamond and common carbonaceous substances is done away by these researches.

A fact which I formerly noticed, the blackening of diamond

* Annalis de Chimie, tone Ixxxiv. p. 241.

4. Sec Bakeriatn Lecture ful 1608. Potassium decomposes the silica in glass by being heated in contact with it; and in the case in which equal quantities of potassium were long beated in glass tubes, the one in contact with diamontis, the other alone, that in contact with the diamonds must have acted upon a much greuter surface of glass. 
Some Experiments on the Combusione of the Dicun:mu, 437

by the long continued action of heated 1 sx.... sian, sinced me

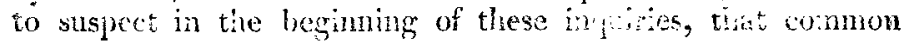
charcoal might owe it enhur, opacit, wh conchestry power, to the circumstuace of its containing ninte portion of the metals of the alkalies, or earths, and piumbage to the iron it contains; but when I found that charcosl mate from oil of turpentine, which left no residme in bume, an charcoal precipitated from carburetted hylrogea ga li: chinite, had the same pioperties, it was necessary to renomce this opinion.

The only chemial afierence perceptible between diamond and the purest cinucoul, is, that the last contains a minute portion of livirogen: but cun a quantity of an element, less in some caces than 560 ing part of the weight of the substance, occasion so great a diference in physical and chemicil characters? This is possible, yet it is contrary to analogy; and ! am more inclined to adopt the opinion of Mr. Temnant, that the difference depends upon crystallization. Transparent solid boties are in general non-conductors of electricity, and it is probable that the same corpuscular arrangements which give to matter the power of transmitting and polarizing light, are likewise counected with its relations to electricity; and water, the hydrates of the alkalies, and a number of other bodies which are conductors of electricity when fluid, become non-conductors in their crystallized form.

The power possessed by certain carbonaceous substances of absorbing gases, and sceparating colouring natters from fuids, is probably mechanical and dependent upon their porous nature; for it belongs in the lighest degree to vegetable and animal charcoal, and it does not exist in plumbago, coke, or anthracolite.

The same conclusions respecting the composition of carbonic acid may be drawn from these experiments, as from those of Messrs. Allen and Pepys, and Theodore de Saussure. If the ealculations be founded upon the difference of the weights of oxygen and carbonic acid gases, which appears the most exact method, carbonic acid gas will contain, according to the estimate of the mean specific of the gravities of the two gases given by M. Theodore de Saussure*, thirty parts of oxygen, or two definite proportions, to $l l \cdot 3$ parts of carbon, or one definite proportion.

Supposing the diminution of the oxygen produced in the experiments on the common carbonaceons substances entirely oceasioned by the formation of water, it is easy to calculate the proportions of hydrogen in them; but in the case of plumbago

"Annales de Chimie, tome 1xxi. par. 261. This rstimation is the same as that I bave givel. Elements of Chem. Phil. pag. 305 .

$$
\mathrm{E} \text { e } 3
$$

there 
there is probably a diminution of oxygen, from the oxidation of the iron; and it is not certain that the ashes afforded by the charcoal from vegetable substances exist in it in the state of earths and alkalies: and as the quantity of hydrogen varies according to the degiee of heat to which charcoal has been exposed, it is almost useless to attempt to assign its proportion in any particular case, especially when the largest portion is so extrencly minute.

The nature of the chemical difference between the diamond and other carbonaceous substances may be demonstrated by an1other process, namely, igniting them in chlorine ; when common well burnt charcoal, or plumbago from Cumberland, is intensely ignited in chlorine, white fumes are immediately perceived in consequence of the production of muriatic acid gas by the hydrogen, which acid precipitates the aqueous vapour in the chlorine; but the diamond occasions no such effect. A small diamond, weighing 45 of a grain, was kept in a state of intense igrition by the great lens of the Florentine Museum for more than half an hour; but the gas suffered no change, and the diamond had undergone no diminution of weight, and was not altered in appearance.

Chareal, after being intensely ignited in chlorine, is not altered in its conducting power or colour; and this circumstance. is in favour of the opinion, that the minute quantity of hydrogen is not the cause of the great difference between the physical properties of the dianond and charcoal.

\section{New Oullines of Chemical Philosophy. By Ez. Wazker, Esq. of Lynn, Norfolk.}

[Continued from p. 355.]

W HAT has been arlvanced upon evaporation in my last paper, receives considerable support from a series of experiments carried on by Mir. Six, to investigate the variations of local heat.

Cin Fecenber 19, 178\%, this gentleman disposed of three thermiraters, of a peculiar construction, in the following manner; one in his garden; one on the top of St. Thomas's hill, at fit tres feet fron the ground, which was nearly on a level with a thind piaced on the top of the high tower of Canterbury cathedral, at about 220 feet from the ground. From observations taken wirn these instruments he foulid, that

"The incal variations in the day time seemed to be regulated by the gener.l degree of heat only, without being affected by any other paticular disposition of the atmosphere, or the clear- 